\title{
Detailed characterizations of the new Mines Douai comparative reactivity method instrument via laboratory experiments and modeling
}

V. Michoud et al.

Correspondence to: S. Dusanter (sebastien.dusanter@mines-douai.fr) and V. Michoud (vincent.michoud@mines-douai.fr)

The copyright of individual parts of the supplement might differ from the CC-BY 3.0 licence. 
Supplementary material 1: Comparison between measured and calculated total $\mathrm{OH}$ reactivity values for two different gas mixtures: Non-Methane Hydrocarbons (NMHCs) and Oxygenated VOCs (OVOCs)

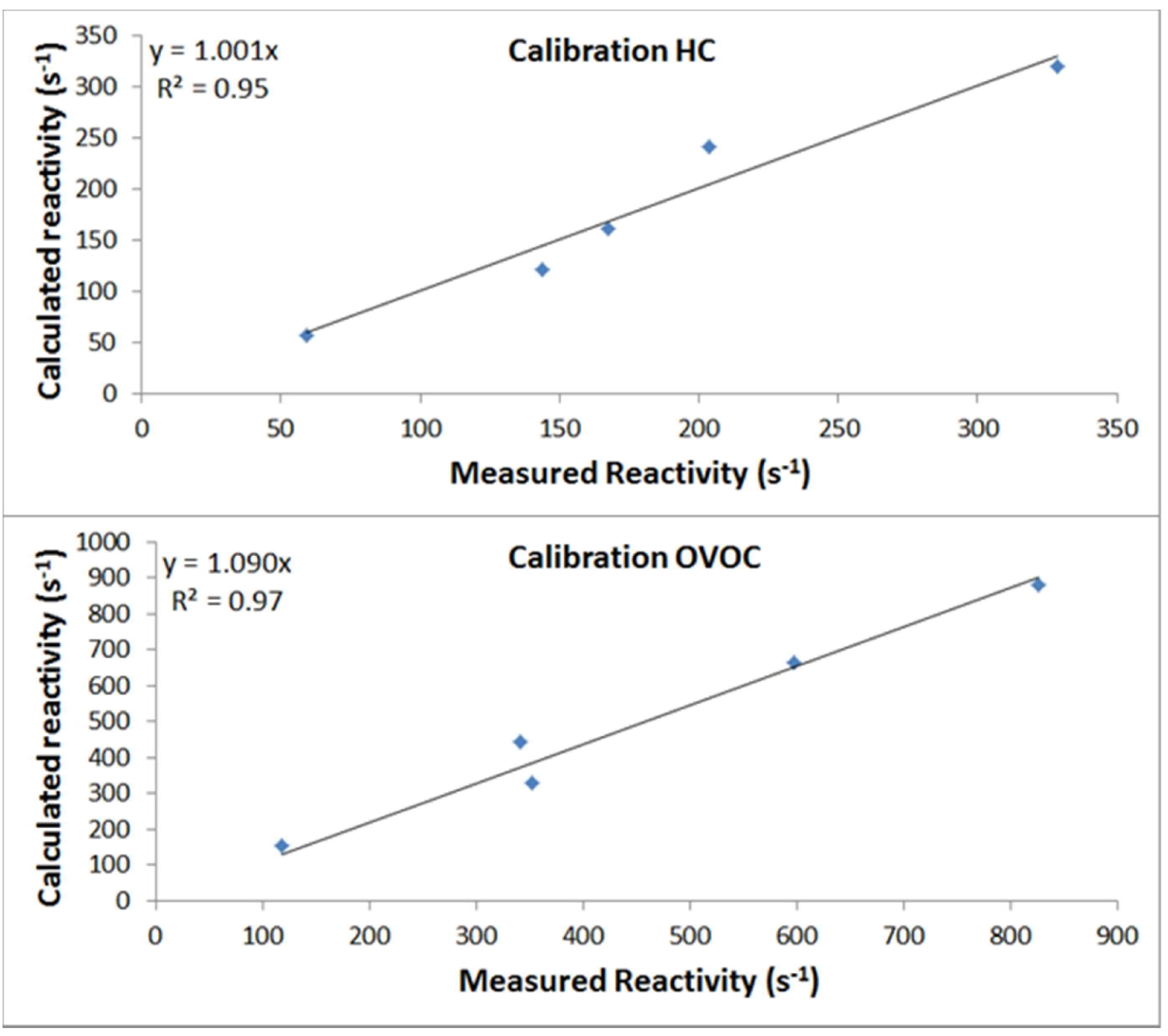

Figure S1: Scatter plot of calculated-to-measured $\mathrm{OH}$ reactivity for two different gas mixtures: NMHCs (top panel) and OVOCs (bottom panel) at pyrrole to $\mathrm{OH}$ ratios of 1.9 and 1.8 , respectively. Chemical compositions of these mixtures are given in table $\mathrm{S} 1$. The measured $\mathrm{OH}$ reactivity corresponds to the total $\mathrm{OH}$ reactivity measured by MD-CRM and corrected for changes in humidity between $\mathrm{C} 2$ and $\mathrm{C} 3$ and for not operating the instrument under pseudo first order conditions. Correction for dilution is not performed since it is accounted for in the calculated $\mathrm{OH}$ reactivity.

Table S1: Chemical composition of the OVOC and NMHC mixtures.

\begin{tabular}{lc||lc}
\hline Species OVOC mixture & Mixing ratios $(\mathrm{ppm})$ & Species NMHC mixture & Mixing ratios $(\mathrm{ppm})$ \\
\hline Methanol & 2.15 & Acetonitrile & 0.63 \\
Acetaldehyde & 1.43 & Acrylonitrile & 0.51 \\
Acetone & 4.50 & Benzene & 0.96 \\
Methyl Ethyl Ketone & 1.40 & Toluene & 0.91 \\
2-Methylfuran & 1.51 & EthylBenzene & 0.80 \\
Acrolein & 1.48 & 1,2,4-TrimethylBenzene & 0.52 \\
Methacrolein & 1.65 & Styrene & 0.71 \\
Methyl Vinyl Ketone & 1.54 & Alpha-Pinene & 1.07 \\
3-Methyl-2-buten-1-ol & 0.60 & Methyl Sulfur & 1.14
\end{tabular}


Table S2: Reactions included in the simple mechanism (see section 3.1 of the main manuscript).

\begin{tabular}{l||c}
\hline Reactions & Bimolecular rate constants $\left(\mathrm{cm}^{3}\right.$ molecules $\left.{ }^{-1} \mathrm{~s}^{-1}\right)$ \\
\hline $\mathrm{H}+\mathrm{O}_{2}=\mathrm{HO}_{2}$ & $7.5 \times 10^{-11}$ \\
$\mathrm{OH}+\mathrm{VOC}=\mathrm{RO}_{2}$ & $5.0 \times 10^{-12}$ \\
$\mathrm{OH}+\mathrm{Pyrrole}=\mathrm{RO}_{2}$ & $1.2 \times 10^{-10}$ \\
${ }^{*} \mathrm{RO}_{2}+\mathrm{RO}_{2}=$ & $3.4 \times 10^{-13}$ \\
${ }^{*} \mathrm{RO}_{2}+\mathrm{HO}_{2}=$ & $5.2 \times 10^{-12}$ \\
$\mathrm{RO}_{2}+\mathrm{NO}=\mathrm{RO}+\mathrm{NO}_{2}$ & $7.7 \times 10^{-12}$ \\
$\mathrm{RO}^{2} \mathrm{O}_{2}=\mathrm{HO}_{2}$ & $1.9 \times 10^{-15}$ \\
${ }^{*}$ the formation of a product is not accounted for in the mechanism &
\end{tabular}

In addition to the reactions shown in Table S2, inorganic reactions from IUPAC 2001 have been added in the mechanism, leading to a total of 42 reactions. 
Supplementary material 2: Experiments performed to investigate the NO artifact in the presence of VOC reactivity - addition of ethane and isoprene

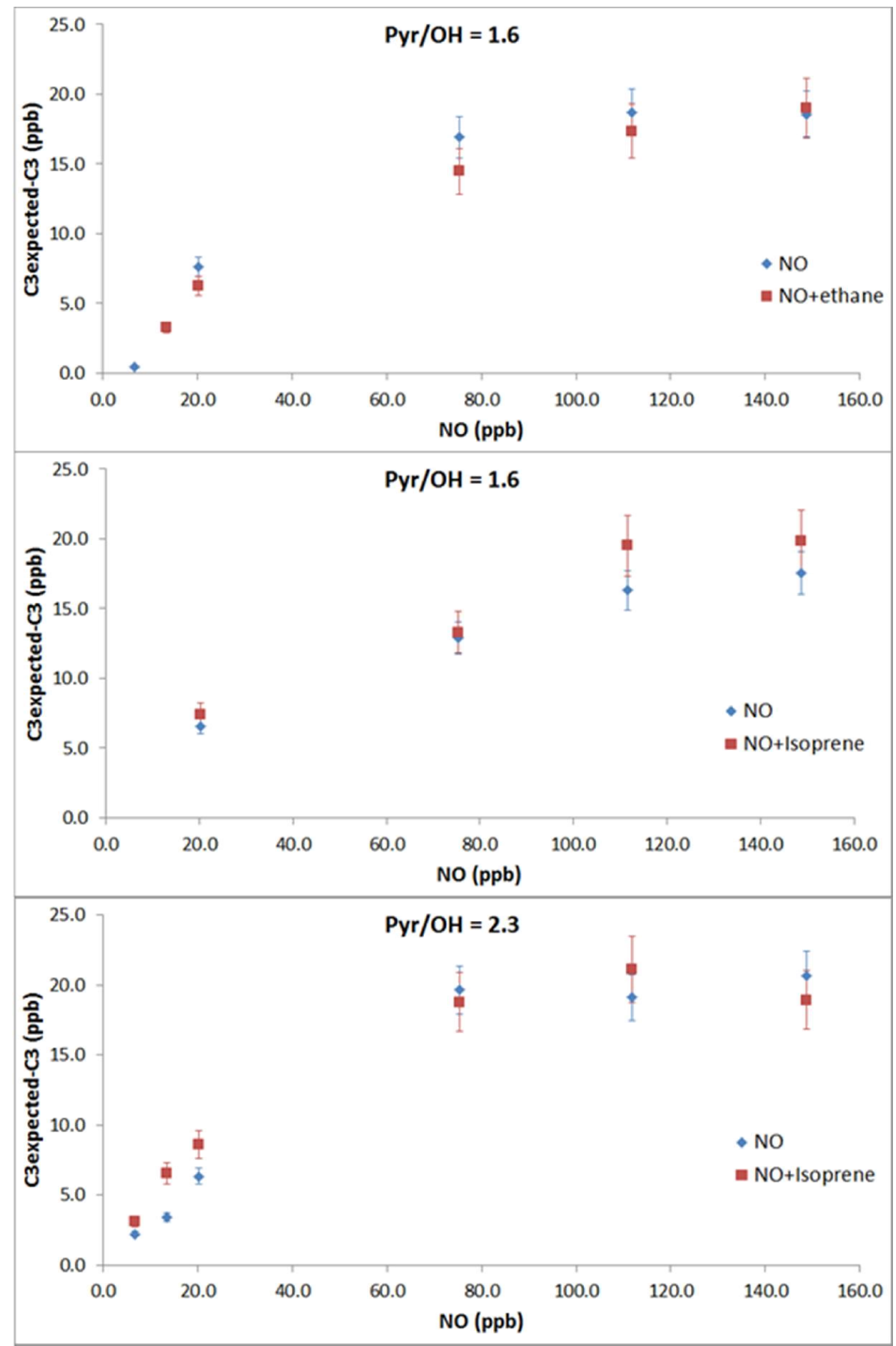

Figure S2: Changes in $\mathrm{C} 3(\Delta \mathrm{C} 3=\mathrm{C} 3$ expected $-\mathrm{C} 3$ measured $)$ as a function of NO in the reactor with (red) and without (blue) addition of a VOC. These experiments have been conducted using two different standards (ethane and isoprene) selected for their different kinetic rate constants with $\mathrm{OH}\left(2.410^{-13}\right.$ and $1.010^{-10} \mathrm{~cm}^{3}$ molecules ${ }^{-1} \mathrm{~s}^{-1}$, respectively). The concentrations added were $3.7 \mathrm{ppm}$ and $14.6 \mathrm{ppb}$ for ethane and isoprene, respectively, leading to calculated $\mathrm{OH}$ reactivity values of 22.2 and $36.6 \mathrm{~s}^{-1}$, respectively. Experiments 
made using isoprene have been conducted at two different Pyrrole-to-OH ratios (1.6 and 2.3) to test the influence of this parameter on the NO artifact in the presence of a VOC.

Differences observed in the NO artifact when VOCs are added in the reactor are within experimental uncertainties $(9-11 \%)$, except when NO is low during the isoprene experiment made at a pyrrole-to-OH ratio of 2.3. No clear influence of the Pyrrole-to-OH ratio or of the VOC reactivity has been found on the amplitude of the NO artifact.

\section{Supplementary material 3: Comparison between real and apparent Pyrrole-to- $\mathrm{OH}$ ratios}

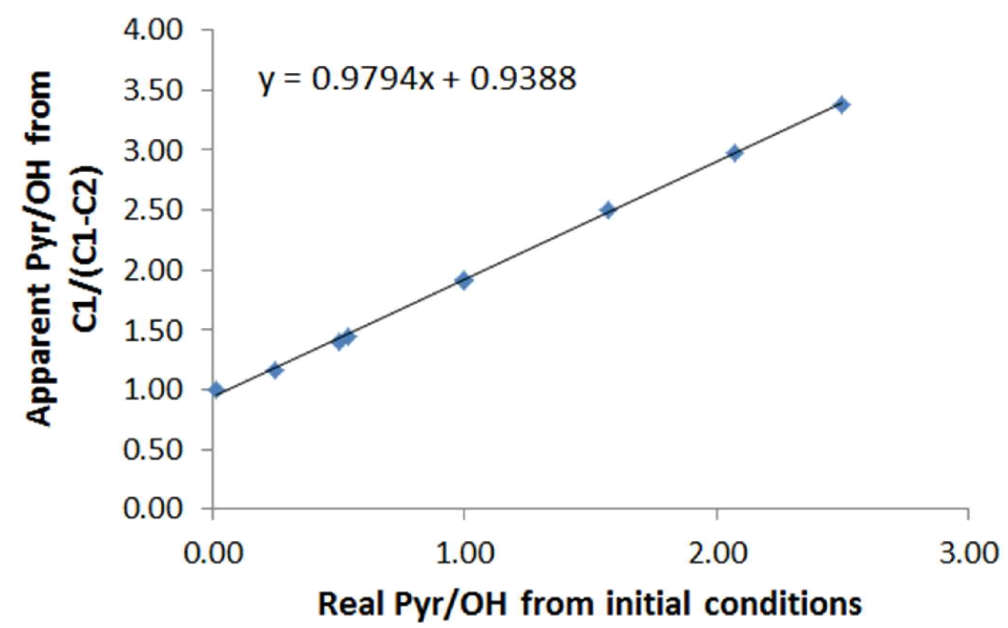

Figure S3: Comparison between real and apparent pyrrole-to-OH ratios for simulations conducted under dry conditions with the simple mechanism presented in section 3.1 of the main manuscript. Apparent pyrrole-to-OH ratios are calculated using Eq. (2), where $\mathrm{C} 1$ is the initial concentration of pyrrole and $\mathrm{C} 2$ the final concentration when $\mathrm{OH}$ has been fully reacted in the simulations. This apparent ratio provides the amount of $\mathrm{OH}$ that has reacted with pyrrole.

This figure shows that running the CRM instrument at an apparent pyrrole-to-OH ratio of 1.52.5 leads to a real ratio of approximately 0.5-1.5. The main manuscript and this supplementary material always refer to the apparent pyrrole-to-OH ratio since it is the measurable quantity.

\section{Supplementary material 4: Experimental measurements of the $\mathrm{OH}$ mixing ratio inside the CRM reactor}

Experiments were conducted to determine the $\mathrm{OH}$ mixing ratio inside the reactor. A large amount of isoprene $(3 \mathrm{ppm})$ was injected inside the reactor in absence of pyrrole with (mercury lamp ON) or without (mercury lamp OFF) OH production. Isoprene was monitored by the PTR-ToFMS instrument at $\mathrm{m} / \mathrm{z}$ 69. Simulations were conducted using MCM to ensure that this level of isoprene allows scavenging more than $97 \%$ of $\mathrm{OH}$ in the reactor. The $\mathrm{OH}$ mixing ratio present within the reactor can be derived from the decrease of isoprene when the $\mathrm{OH}$ production is turned $\mathrm{ON}$. This $\mathrm{OH}$ mixing ratio, referred as "OH experiment", was 
determined at two different pyrrole-to-OH ratios of 1.6 and 3.8. The level of $\mathrm{OH}$ quantified experimentally from $(\mathrm{C} 1-\mathrm{C} 2)$, i.e. the amount of $\mathrm{OH}$ reacting with pyrrole, is referred as " $\mathrm{OH}$ estimated CRM" and is compared to the total mixing ratio of $\mathrm{OH}$ determined experimentally. In addition, the $\mathrm{OH}$ mixing ratio necessary to reproduce the experimental $\mathrm{C} 1-\mathrm{C} 2$ modulation with the model is referred as "OH model". The three $\mathrm{OH}$ mixing ratios are shown in Fig. S4.

As seen in this figure, $\mathrm{OH}$ experiment is higher than the level determined from the $\mathrm{C} 1-\mathrm{C} 2$ modulation but only slightly lower $(\sim 10-20 \%)$ than $\mathrm{OH}$ model (within experimental uncertainties). However, the amount of isoprene injected inside the reactor may not be high enough to scavenge all the $\mathrm{OH}$ radicals if a segregation occurs between the reactants (see supplementary material S8). Some $\mathrm{OH}$ might still react with $\mathrm{HO}_{2}$, leading to a slight underestimation of $\mathrm{OH}$ experiments. From these results, we consider that $\mathrm{OH}$ mixing ratios set in the model to simulate the experimental $\mathrm{C} 1-\mathrm{C} 2$ modulations are representative of the real mixing ratio in the reactor.

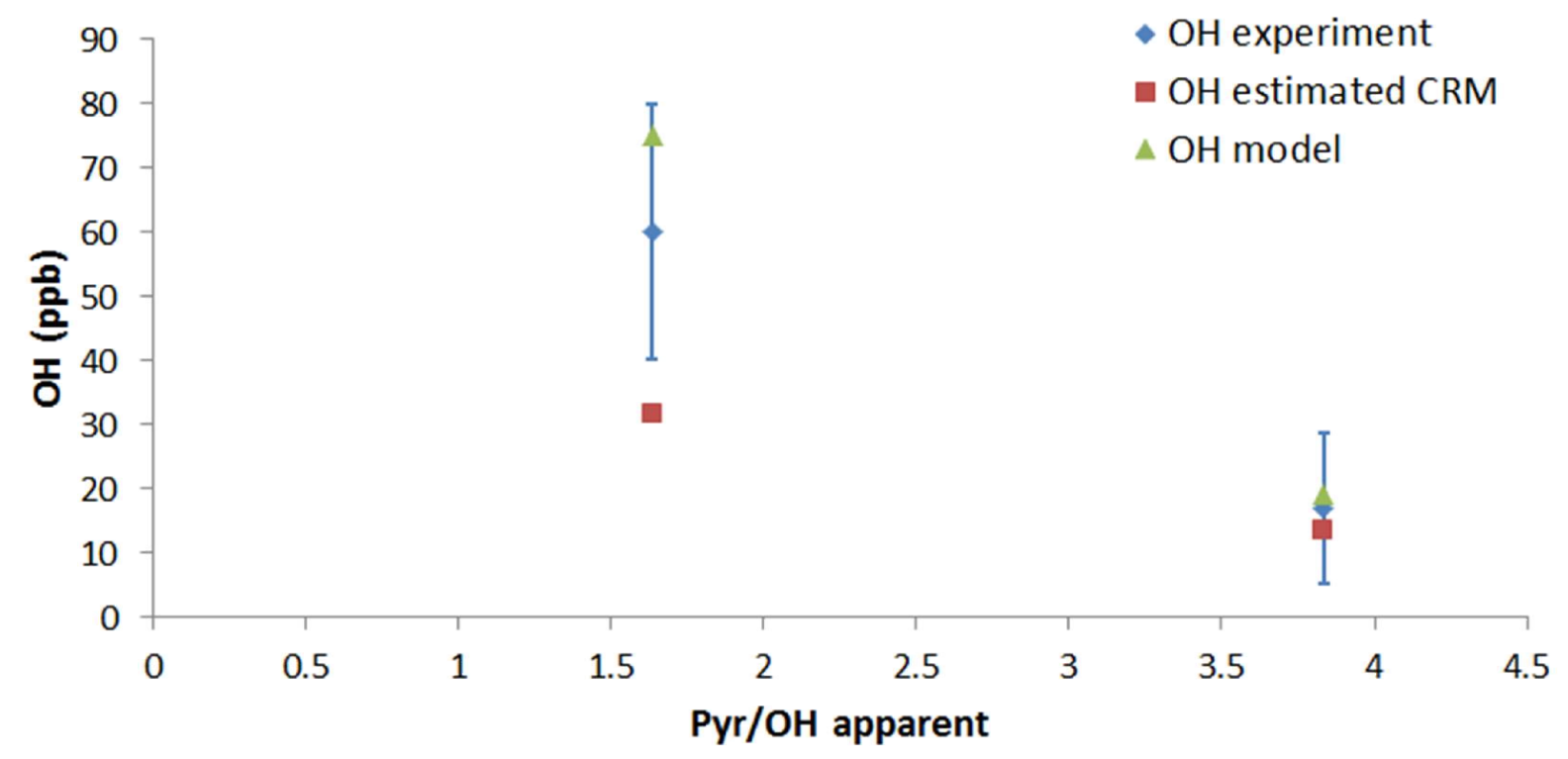

Figure S4: Comparison between $\mathrm{OH}$ mixing ratios determined experimentally ("OH experiment", blue diamonds), calculated from the C1-C2 modulation ("OH estimated CRM", red squares), and estimated from the model ("OH model”, green triangles) at two different pyrrole-to-OH ratios (1.6 and 3.8). Error bars are the measurement precision. Large error bars (33-68\%) are found since these $\mathrm{OH}$ measurements correspond to differences of tens of ppb for an initial mixing ratio of isoprene of approximately $3 \mathrm{ppm}$. 


\section{Supplementary material 5: Influence of humidity on the NO artifact - simulation results}

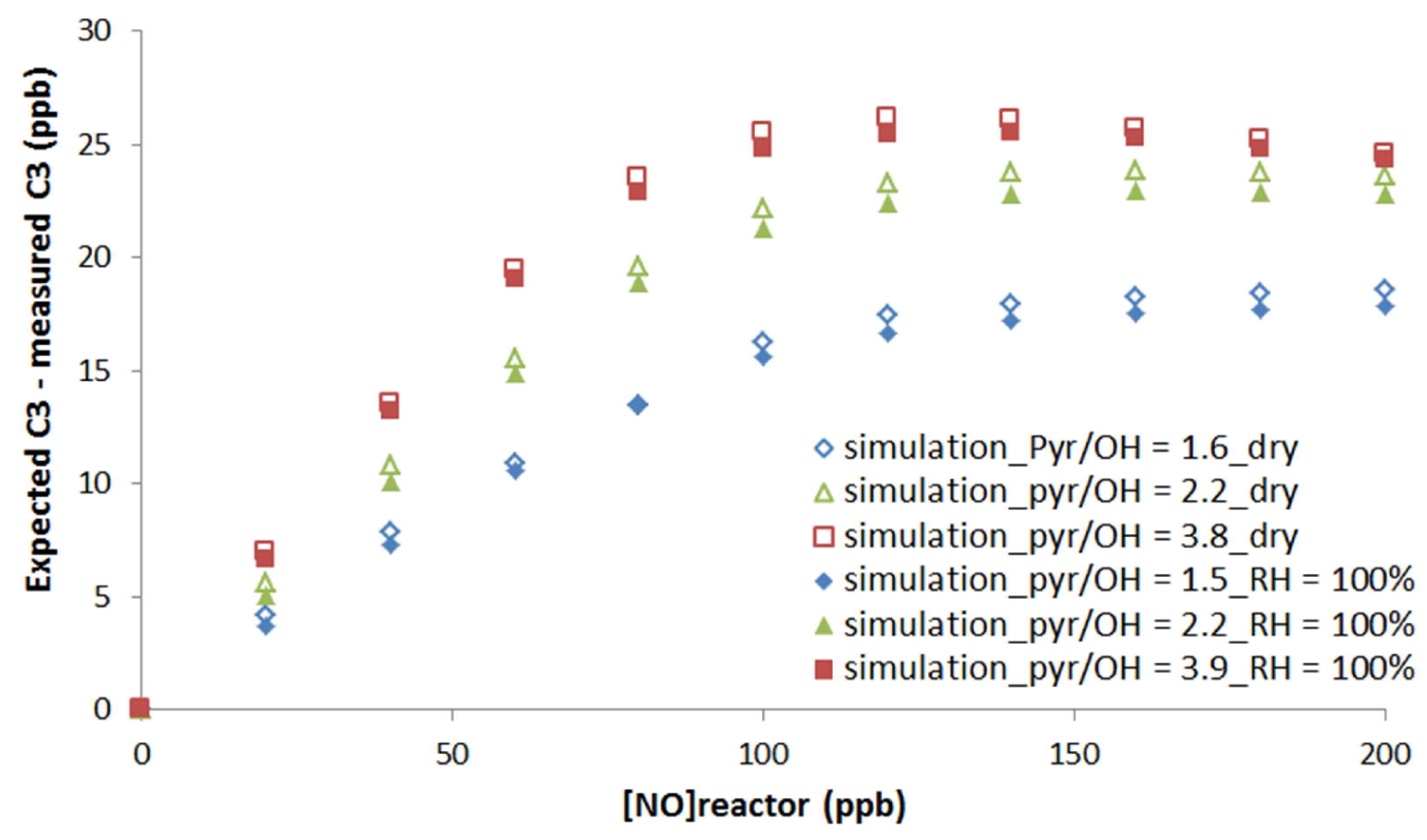

Figure S5: Comparison between simulations performed to investigate the NO artifact under dry (open symbols) and humid (filled symbols) conditions. These simulations were conducted at three different pyrrole-to-OH ratios of 1.5-1.6 (blue diamonds), 2.2 (green triangles), and 3.8-3.9 (red squares), using the simple mechanism and humid conditions corresponding to a relative humidity of $100 \%$.

A small decrease of $\triangle \mathrm{C} 3$ is observed at each pyrrole-to-OH ratio. This can be explained by an enhancement of the reaction rate of $\mathrm{HO}_{2}+\mathrm{HO}_{2}$ in the presence of water, reducing the secondary formation of $\mathrm{OH}$, hence the $\mathrm{NO}$ artifact. 
Supplementary material 6: Influence of adding a gas standard on the NO artifact - simulation results

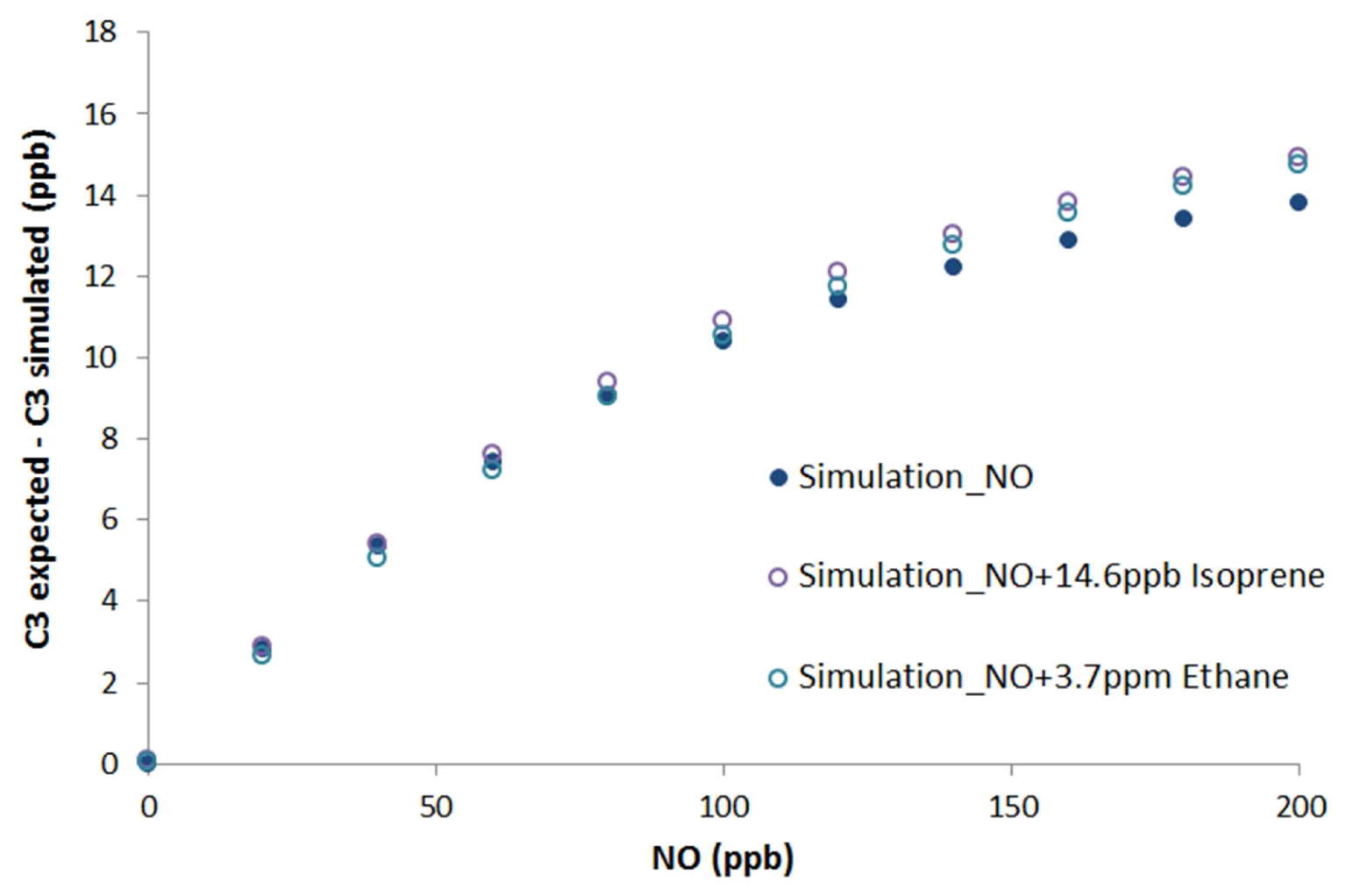

Figure S6: Simulated changes in $\mathrm{C} 3(\Delta \mathrm{C} 3=\mathrm{C} 3$ expected $-\mathrm{C} 3$ simulated $)$ as a function of NO. This figure shows simulations made with (open circles) and without (filled circles) adding a gas standard. These simulations were conducted with the MCM mechanism at a pyrrole-to$\mathrm{OH}$ ratio of 1.4. The gas standards are isoprene $(14.6 \mathrm{ppb})$ and ethane $(3.7 \mathrm{ppm})$, leading to additional $\mathrm{OH}$ reactivities of 36.6 and $22.2 \mathrm{~s}^{-1}$, respectively. 


\section{Supplementary material 7: Influence of the VOC bimolecular rate constant on the correction factor - experimental results}

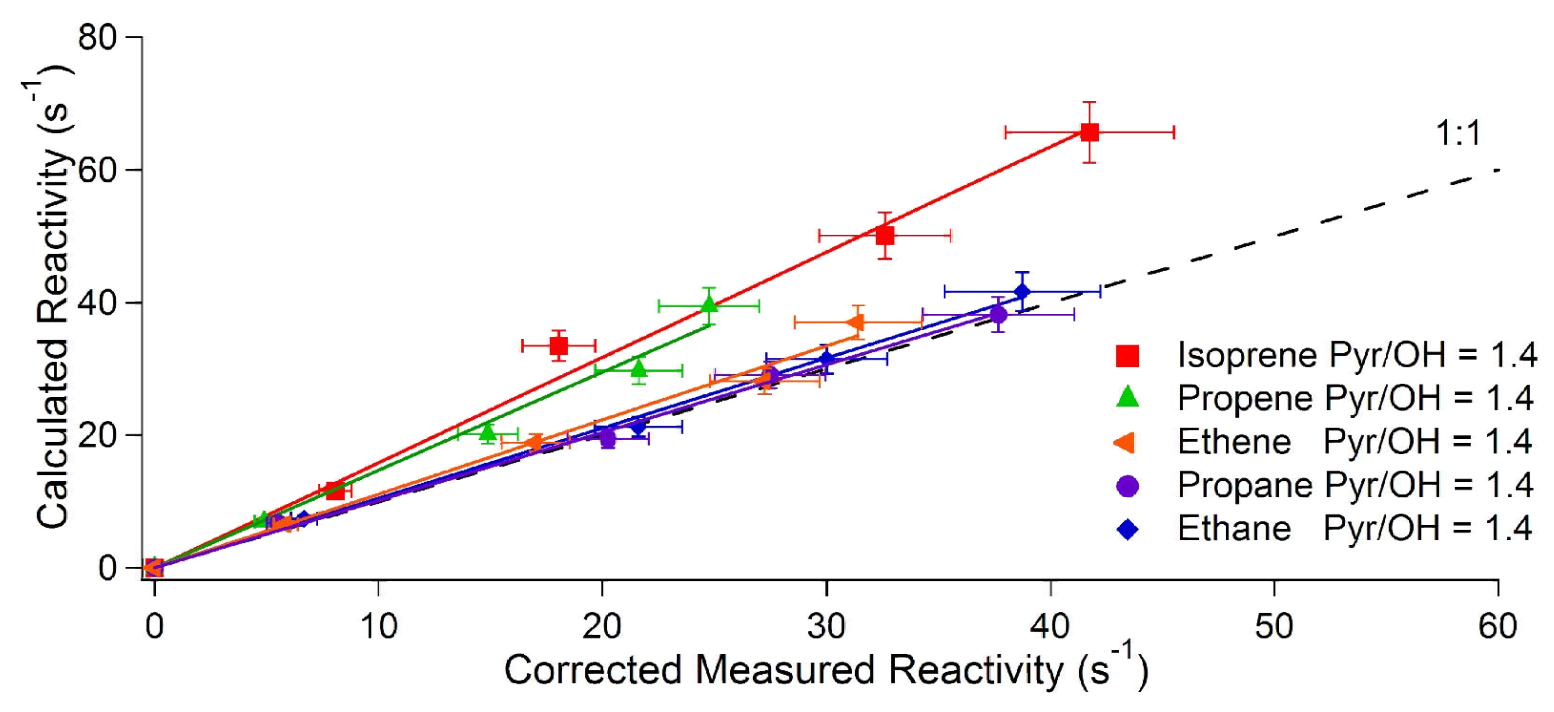

Figure S7: Experimental investigations of the bias caused by not operating the instrument under pseudo first-order conditions. Comparison of calculated (true) $\mathrm{OH}$ reactivity to CRM measurements during the addition of a gas standard into the reactor at a pyrrole-to-OH ratio of 1.4. Results from the addition of five different gas standards (Isoprene: red squares, Propene: green triangles, Ethene: orange triangles, Propane: purple circles, and Ethane: blue diamonds). These gas standards are characterized by reaction rate constants with $\mathrm{OH}$ of $1.0 \times 0^{-10}, 2.9 \times 10^{-}$ ${ }^{11}, 8.5 \times 10^{-12}, 1.1 \times 10^{-12}$, and $2.4 \times 10^{-13} \mathrm{~cm}^{3}$ molecules $^{-1} \mathrm{~s}^{-1}$, respectively.

\section{Supplementary material 8: Potential influence of reactant segregation on the simulations}

One hypothesis to explain the differences observed between measurements and simulations for the bias caused by not operating the instrument under pseudo first-order conditions is a potential segregation of reactants coming from two different injectors $\left(\mathrm{OH}\right.$ and $\mathrm{HO}_{2}$ on one side and pyrrole + reactive trace gases on the other side). To account for this segregation (i.e. inhomogeneity in the reactor), we doubled the reaction rate constants of cross- and selfreactions of radicals (i.e. $\mathrm{HO}_{2}+\mathrm{OH}$ and $\mathrm{HO}_{2}+\mathrm{HO}_{2}$ ), assuming that these reactions are favored by inhomogeneities inside the reactor since all the radicals are injected from the same injector. Figure S8 shows a comparison between base simulations and simulations including reactant segregation as a function of the pyrrole-to-OH ratio. Laboratory derived correction factors are also shown. These simulations suggest that segregation cannot explain the disagreement since a larger difference is found when compared to experimental observations. 


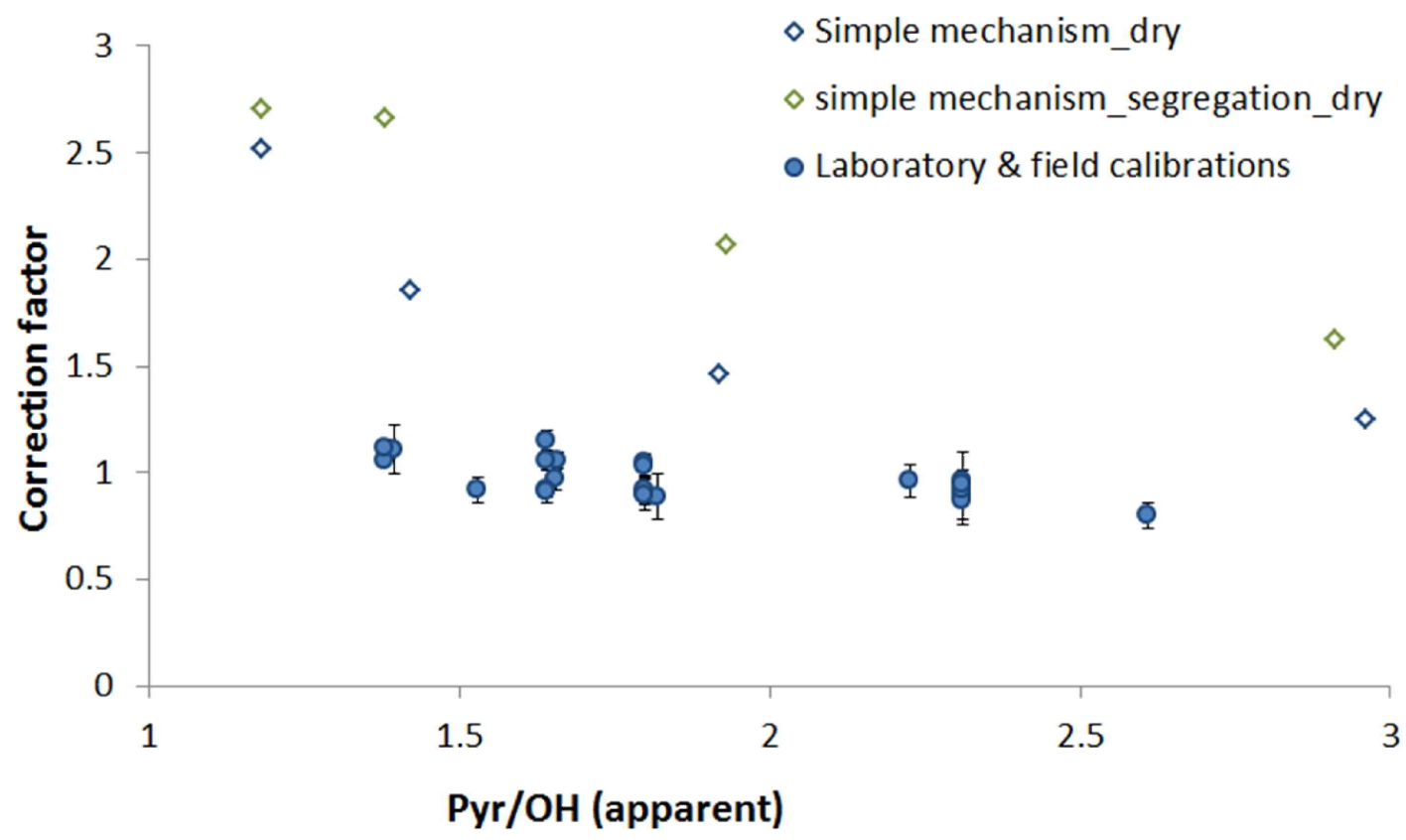

Figure S8: Comparison of simulated and measured correction factors required to correct for not operating the instrument under pseudo first order conditions. Correction factors are shown as a function of the Pyrrole-to-OH ratio. Measured correction factors (blues circles), as well as error bars, are the same than in Fig. 7. The simulated correction factors stem from simulations conducted using the simple mechanism (blue open diamonds) and the simple mechanism including the segregation effect (green open diamonds).

\section{Supplementary material 9: Potential influence of $\mathrm{RO}_{2}+\mathrm{OH}$ reactions on the simulations}

A recent study has proposed the reaction of $\mathrm{CH}_{3} \mathrm{O}_{2}$ with $\mathrm{OH}$ as a potential sink of $\mathrm{CH}_{3} \mathrm{O}_{2}$ in the remote atmosphere (Fittschen et al., 2014). Since high radical concentrations are produced in the CRM reactor, radical-radical reactions may have an important impact on the CRM measurements. We have, therefore, tested the addition of the reaction between peroxy radicals and $\mathrm{OH}$ in the simple mechanism, assuming a reaction rate constant similar to the one of $\mathrm{CH}_{3} \mathrm{O}_{2}$ determined by Bossolasco et al. (2014). Figure S9 shows the comparison between the correction factors derived from base simulations and simulations including the fast $\mathrm{RO}_{2}+\mathrm{OH}$ reactions as a function of the pyrrole-to- $\mathrm{OH}$ ratio. The addition of this reaction in the chemical mechanism leads to an increase of the correction factor and worsen the comparison. 


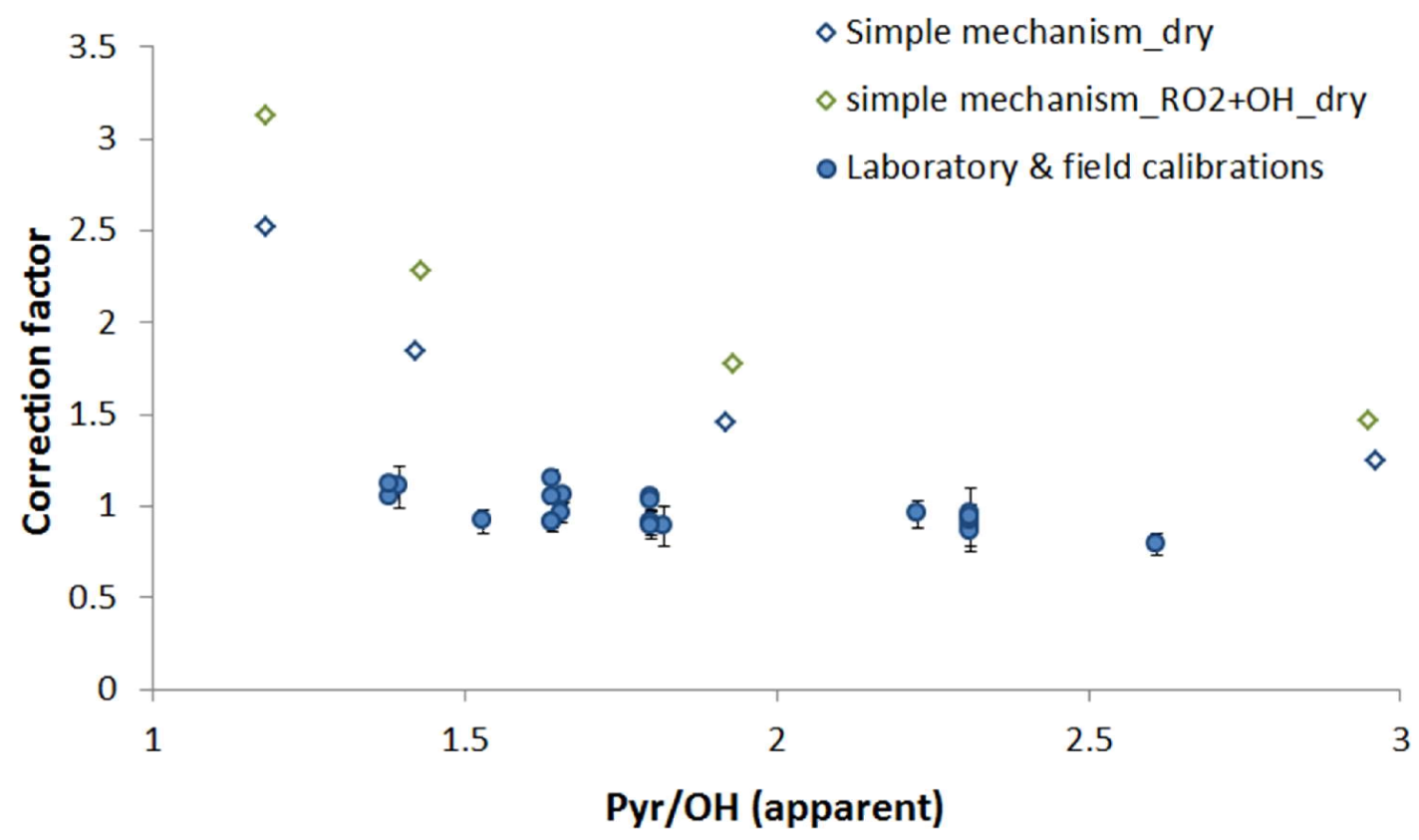

Figure S9: Comparison of the simulated and measured correction factors required to correct for not operating the instrument under pseudo first order conditions. Correction factors are shown as a function of the Pyrrole-to-OH ratio. Measured correction factors (blues circles), as well as error bars, are the same than in Fig. 7. The simulated correction factors stem from simulations conducted using the simple mechanism (blue open diamonds) and the simple mechanism including $\mathrm{RO}_{2}+\mathrm{OH}$ reactions (green open diamonds). The reaction rate constant for $\mathrm{RO}_{2}+\mathrm{OH}$ was set to $2.0 \times 10^{-10} \mathrm{~cm}^{3}$ molecules ${ }^{-1} \mathrm{~s}^{-1}$, corresponding to the rate constant of the reaction of $\mathrm{CH}_{3} \mathrm{O}_{2}+\mathrm{OH}$ (Bossolasco et al., 2014).

\section{Supplementary material 10: Potential influence of uncertainties associated to radical-radical reaction rate constants on the simulations}

From the two previous tests (S8-S9), it appears that enhancing radical-radical reaction rates leads to an increase of the correction factors, which worsen the model-experiment comparison. One can imagine that an overestimation of reaction rate constants of these reactions can contribute to the discrepancies observed between measurements and simulations. To test the influence of uncertainties associated to radical-radical reaction rate constants, simulations were performed with a reduction of $20 \%$ and $50 \%$ of the reaction rate constant for $\mathrm{HO}_{2}+\mathrm{OH}$. Figure $\mathrm{S} 10$ shows the comparison between measured correction factors, base simulations, and simulations where a reduction of the reaction rate constant was made. This figure shows that a decrease of the $\mathrm{HO}_{2}+\mathrm{OH}$ reaction rate constant allows to decrease the modeled correction factors and to get a better agreement with experimental observations. However, a reduction of the rate constant by $20 \%$ is not sufficient to reconcile measurements and simulations. Even a reduction of $50 \%$, which is very unlikely, leads to simulated correction factors that are still slightly higher than the measurements. Therefore, the uncertainty of reaction rate constants of radical-radical reactions cannot totally explain the discrepancies between simulations and measurements. 


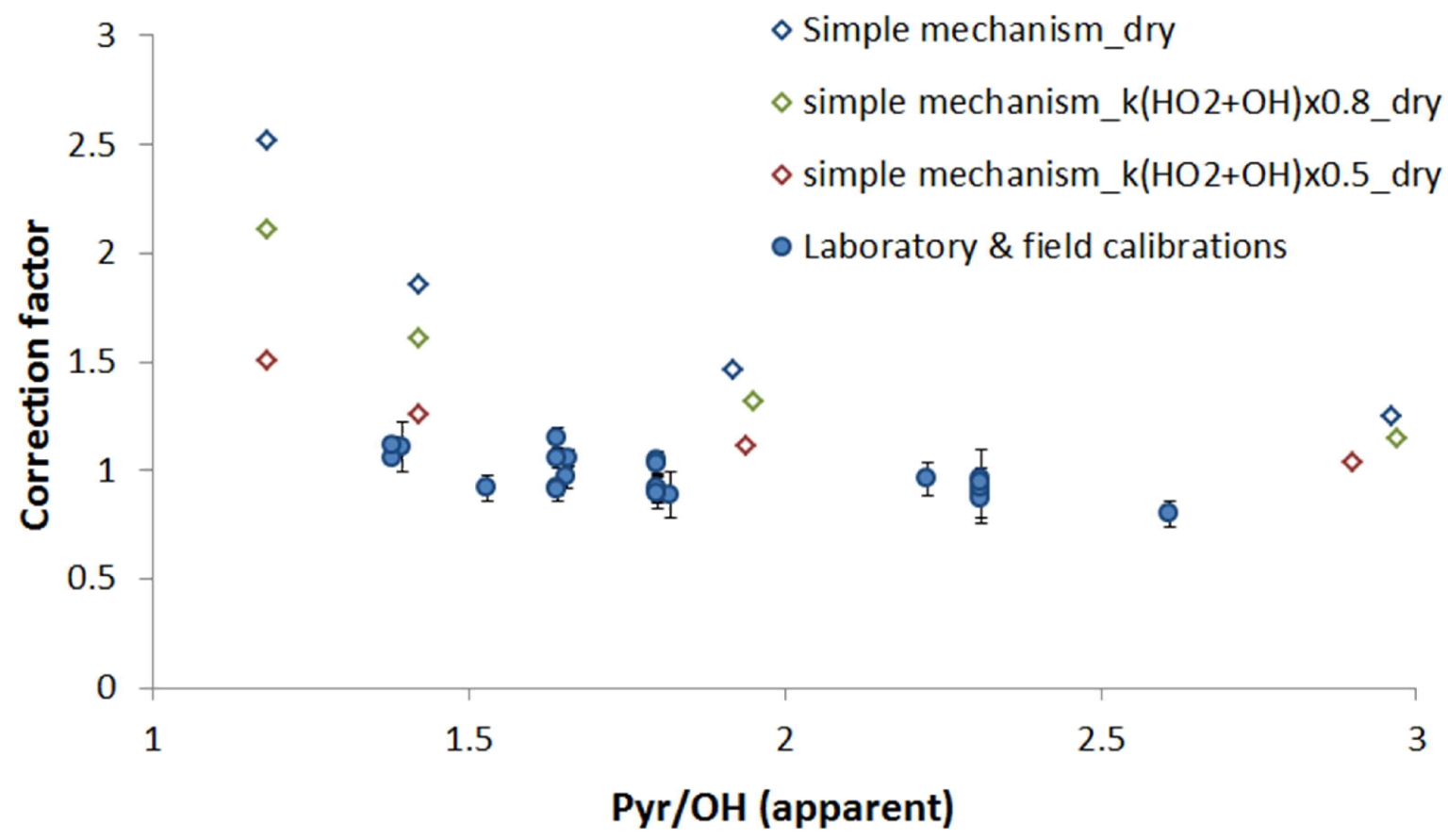

Figure S10: Comparison of the simulated and measured correction factors required to correct for not operating the instrument under pseudo first order conditions. Correction factors are shown as a function of the Pyrrole-to-OH ratio. Measured correction factors (blues circles), as well as error bars, are the same than in Fig. 7. The simulated correction factors stem from simulations conducted using the base simple mechanism (blue open diamonds) and the simple mechanism modified to reflect a slower reaction rate constant for $\mathrm{HO}_{2}+\mathrm{OH}$ (green open diamonds: $20 \%$ reduction, red open diamonds: $50 \%$ reduction).

\section{Supplementary material 11: Potential influence of a higher proportion of $\mathrm{HO}_{2}$ compared to $\mathrm{OH}$ on the simulations}

In all the simulations presented in the main paper and above, we assumed similar concentrations of $\mathrm{HO}_{2}$ and $\mathrm{OH}$ since water photolysis produces similar amounts of these radicals. However, it is likely that a larger amount of $\mathrm{OH}$ radicals is lost on the walls of the injector compared to $\mathrm{HO}_{2}$. Therefore, a $\mathrm{HO}_{2}-$ to-OH ratio higher than unity might be observed inside the reactor. The influence of a higher proportion of $\mathrm{HO}_{2}$ compared to $\mathrm{OH}$ has been tested with the simple mechanism by setting initial $\mathrm{HO}_{2}$ concentrations higher by $20 \%$ than $\mathrm{OH}$ concentrations.

Figure S11 shows the comparison between measured values, base simulations, and simulations where initial $\mathrm{HO}_{2}$ concentrations are higher than initial $\mathrm{OH}$ concentrations by $20 \%$. A higher proportion of $\mathrm{HO}_{2}$ leads to higher simulated correction factors, which worsen the comparison. 


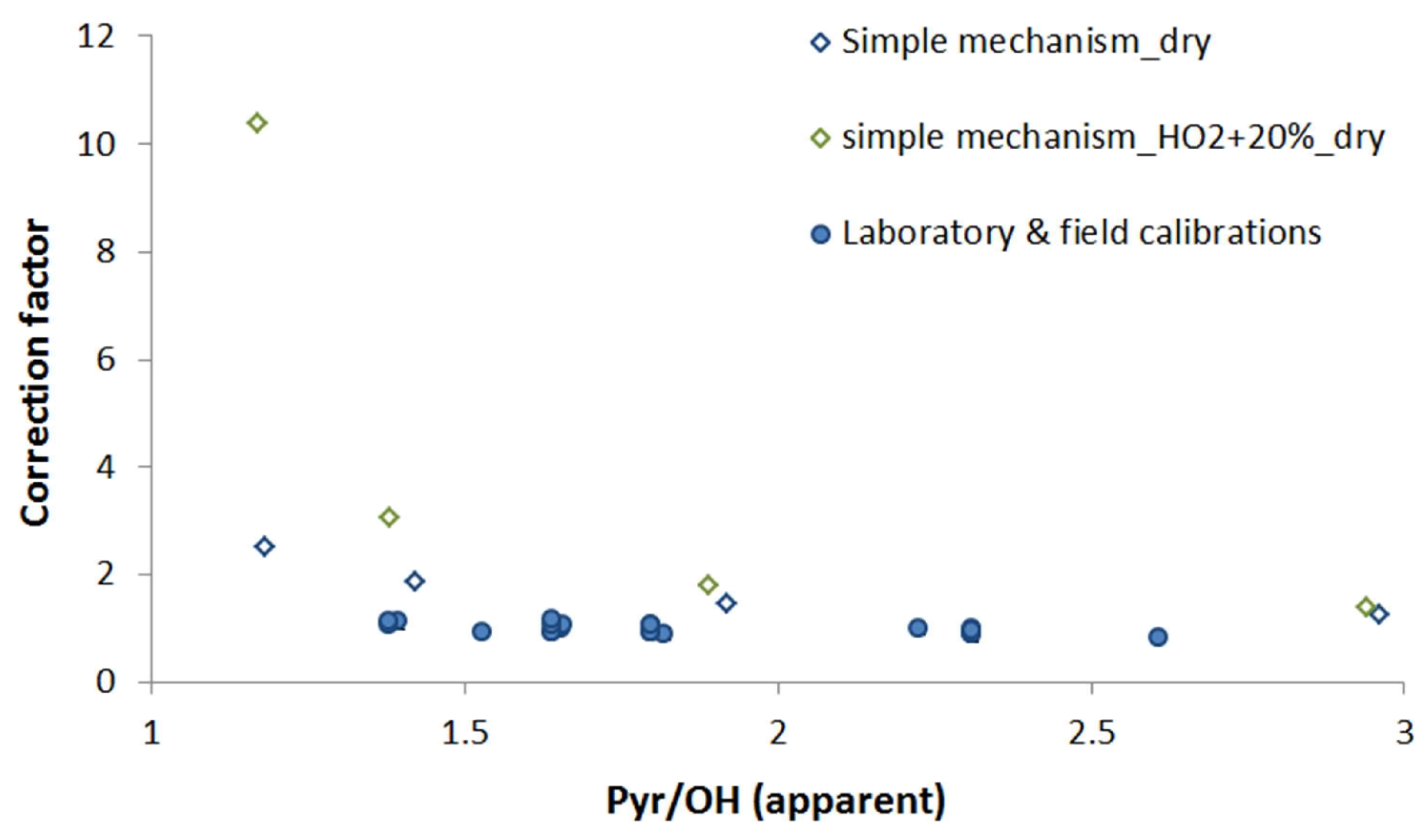

Figure S11: Comparison of simulated and measured correction factors required to correct for not operating the instrument under pseudo first order conditions. Correction factors are shown as a function of the Pyrrole-to-OH ratio. Measured correction factors (blues circles), as well as error bars (hardly visible), are the same than in Fig. 7. The simulated correction factors stem from simulations conducted using the simple mechanism assuming the same concentration for $\mathrm{OH}$ and $\mathrm{HO}_{2}$ (blue open diamonds) and $20 \%$ more $\mathrm{HO}_{2}$ than $\mathrm{OH}$ (green open diamonds).

\section{Supplementary material 12: Potential influence of $\mathrm{O}_{3}$ inside the reactor on the simulations}

All the simulations presented in this work have been performed without $\mathrm{O}_{3}$. However, photolysis of $\mathrm{O}_{2}$ from the mercury lamp emission at $184.9 \mathrm{~nm}$ may occur inside the reactor and may lead to the formation of a significant amount of $\mathrm{O}_{3}$. In this context, the influence of $\mathrm{O}_{3}$ was tested for both the pseudo first order correction and the $\mathrm{NO}$ artifact. The $\mathrm{O}_{3}$ mixing ratio was set at $200 \mathrm{ppb}$ in the simulations, which corresponds to the mixing ratio measured using an ozone analyzer (Environnement-SA, model O3-42M) at the exhaust of the reactor under dry conditions and the mercury lamp ON.

Figure S12.1 shows the comparison between measured correction factors required to correct for not operating the instrument under pseudo first order conditions, base simulations, and simulations where initial $\mathrm{O}_{3}$ mixing ratios were set to $200 \mathrm{ppb}$. This figure shows that the presence of $\mathrm{O}_{3}$ has almost no impact on the simulated correction factors. This can be explained by the fact that the kinetic rate constant for the reaction between Pyrrole and $\mathrm{O}_{3}$ is seven orders of magnitude lower than the rate constant for the reaction between Pyrrole and $\mathrm{OH}$ while initial mixing ratios of $\mathrm{O}_{3}$ are only a factor 2.3 to 19 higher than initial $\mathrm{OH}$ mixing ratios. Furthermore, these simulations indicate that the impact of the $\mathrm{O}_{3}+\mathrm{HO}_{2} \rightarrow \mathrm{OH}$ reaction has only a small impact on CRM simulations, probably due to a slow reaction rate, even with high mixing ratios of $\mathrm{HO}_{2}(27-220 \mathrm{ppb})$ and $\mathrm{O}_{3}(200 \mathrm{ppb})$ inside the reactor. 


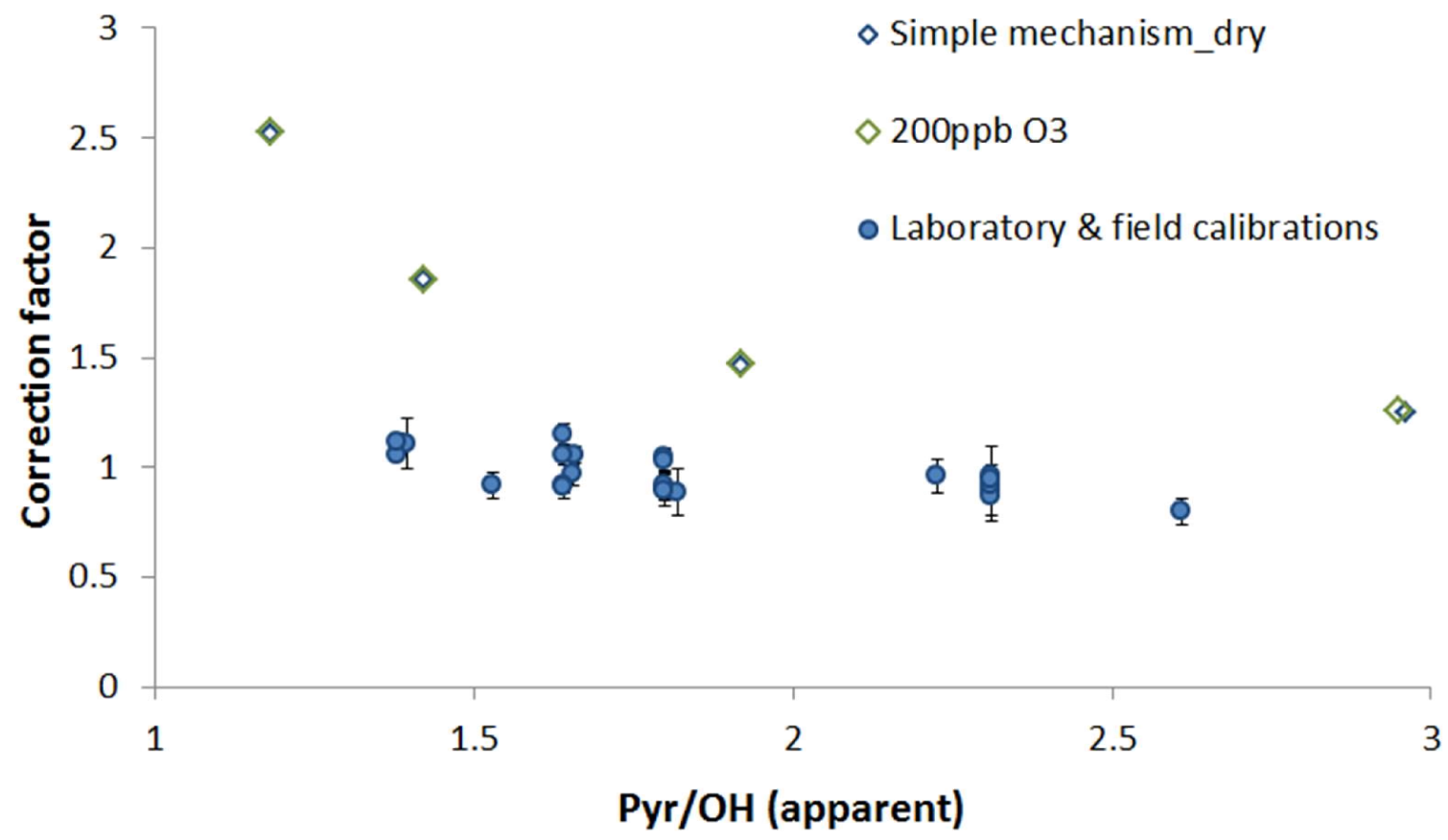

Figure S12.1: Comparison of simulated and measured correction factors required to correct for not operating the instrument under pseudo first order conditions. Correction factors are shown as a function of the Pyrrole-to-OH ratio. Measured correction factors (blues circles), as well as error bars, are the same than in Fig. 7. The simulated correction factors stem from simulations conducted using the base simple mechanism (blue open diamonds) and the simple mechanism where the initial mixing ratio of $\mathrm{O}_{3}$ was set to $200 \mathrm{ppb}$ (green open diamonds).

Figure S12.2 displays the comparison between experimental and simulated results for the NO artifact. Simulations were performed using the MCM mechanism and initialized with an $\mathrm{O}_{3}$ mixing ratios of $200 \mathrm{ppb}$. This figure shows that the presence of ozone leads to a decrease of the NO artifact by approximately $2.5 \%$, independent of the pyrrole-to-OH ratio. 


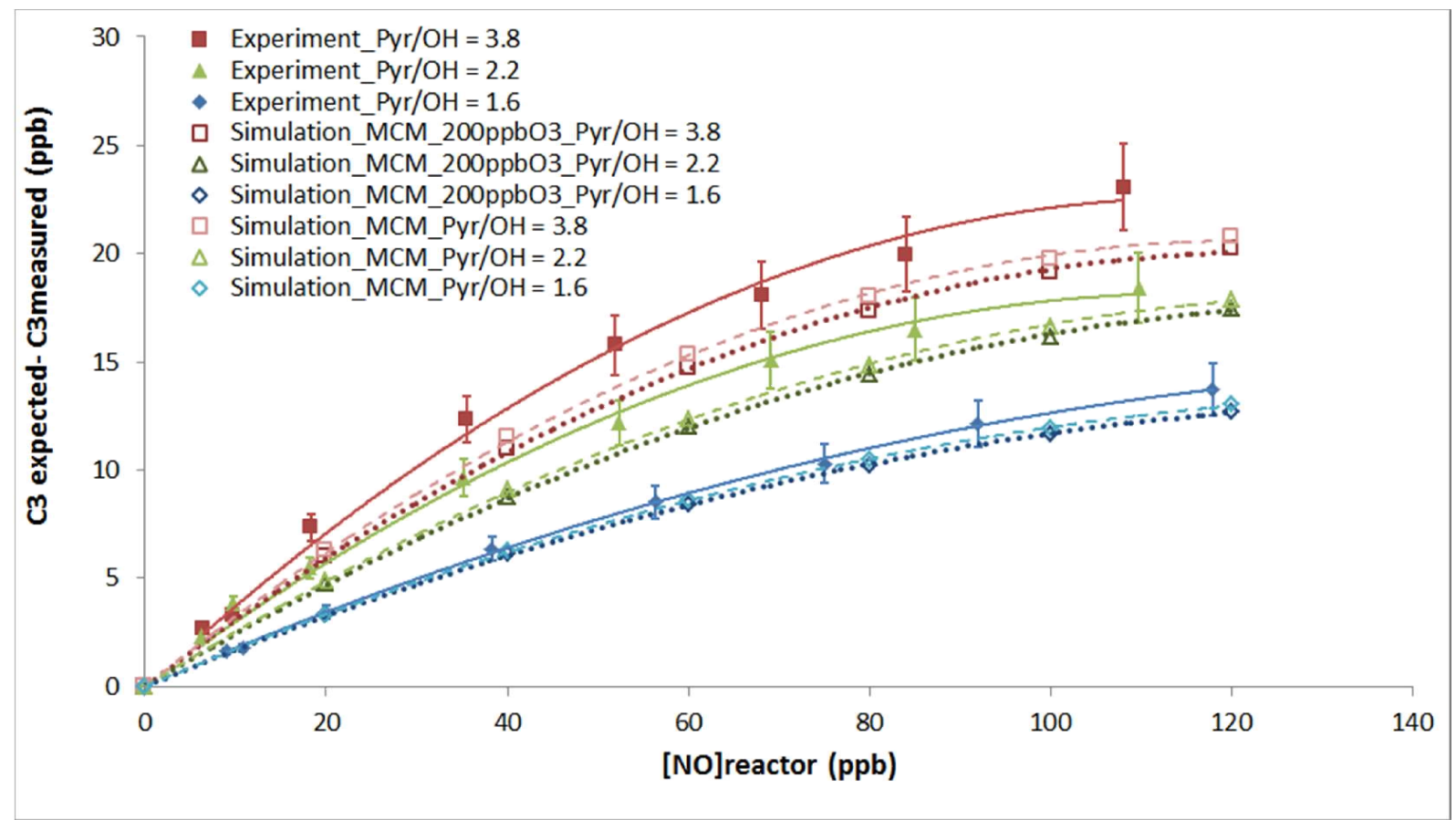

Figure S12.2: Comparison of laboratory observations to model simulations for the NO artifact. Experimental (filled symbols and solid lines) and simulated (open symbols and dashed or dotted lines) results are shown for the changes in $\mathrm{C} 3(\Delta \mathrm{C} 3=\mathrm{C} 3$ expected $-\mathrm{C} 3$ measured) as a function of NO. Experimental values are the same than in Fig. 5. Model values are from simulations made using the base MCM mechanism (open lighter symbols and dashed lines) and the MCM mechanism where the initial $\mathrm{O}_{3}$ concentrations was set to $200 \mathrm{ppb}$ (open darker symbols and dotted lines).

\section{Supplementary material 13: Potential influence of a lower proportion of $\mathrm{HO}_{2}$ compared to $\mathrm{OH}$ on the simulations}

As described in the supplement $\mathrm{S} 12$, a significant mixing ratio of $\mathrm{O}_{3}(\sim 200 \mathrm{ppb})$ is produced inside the reactor from the photolysis of $\mathrm{O}_{2}$. Therefore, the ozone produced can lead to a production of $\mathrm{OH}$ inside the reactor from its photolysis $\left(\mathrm{O}_{3}+\mathrm{h} \nu \rightarrow \mathrm{O}^{1} \mathrm{D}+\mathrm{O}_{2}\right.$ followed by $\mathrm{O}^{1} \mathrm{D}+\mathrm{H}_{2} \mathrm{O} \rightarrow 2 \mathrm{OH}$ ). This $\mathrm{OH}$ source is free of $\mathrm{HO}_{2}$ production. If a non-negligible fraction of $\mathrm{OH}$ comes from this $\mathrm{OH}$ source, then the $\mathrm{OH}$ mixing ratio may be higher than $\mathrm{HO}_{2}$. Therefore, the influence of a lower proportion of $\mathrm{HO}_{2}$ compared to $\mathrm{OH}$ was also tested with the simple mechanism by setting initial $\mathrm{HO}_{2}$ concentrations lower by $25 \%$ than $\mathrm{OH}$ concentrations.

Figure S13 displays the comparison between measured values, base simulations, and simulations where $\mathrm{HO}_{2}$ concentrations were set lower by $25 \%$ than $\mathrm{OH}$ concentrations. This figure shows that a lower proportion of $\mathrm{HO}_{2}$ leads to lower simulated correction factors. However, it cannot fully explain the discrepancies. Furthermore, a much lower proportion of $\mathrm{HO}_{2}$ compared to $\mathrm{OH}$ is not likely since the photolysis of $\mathrm{H}_{2} \mathrm{O}$ inside the injector will likely bring a larger amount of $\mathrm{HO}_{2}$ compared to $\mathrm{OH}$ inside the reactor, which would partly balance the absence of $\mathrm{HO}_{2}$ production from $\mathrm{O}_{3}$ photolysis. It is worth noting that a reduction of $\mathrm{HO}_{2}$ by $25 \%$ would also result in a reduction of the NO artifact by approximately $6 \%$ using the MCM mechanism (not shown). 


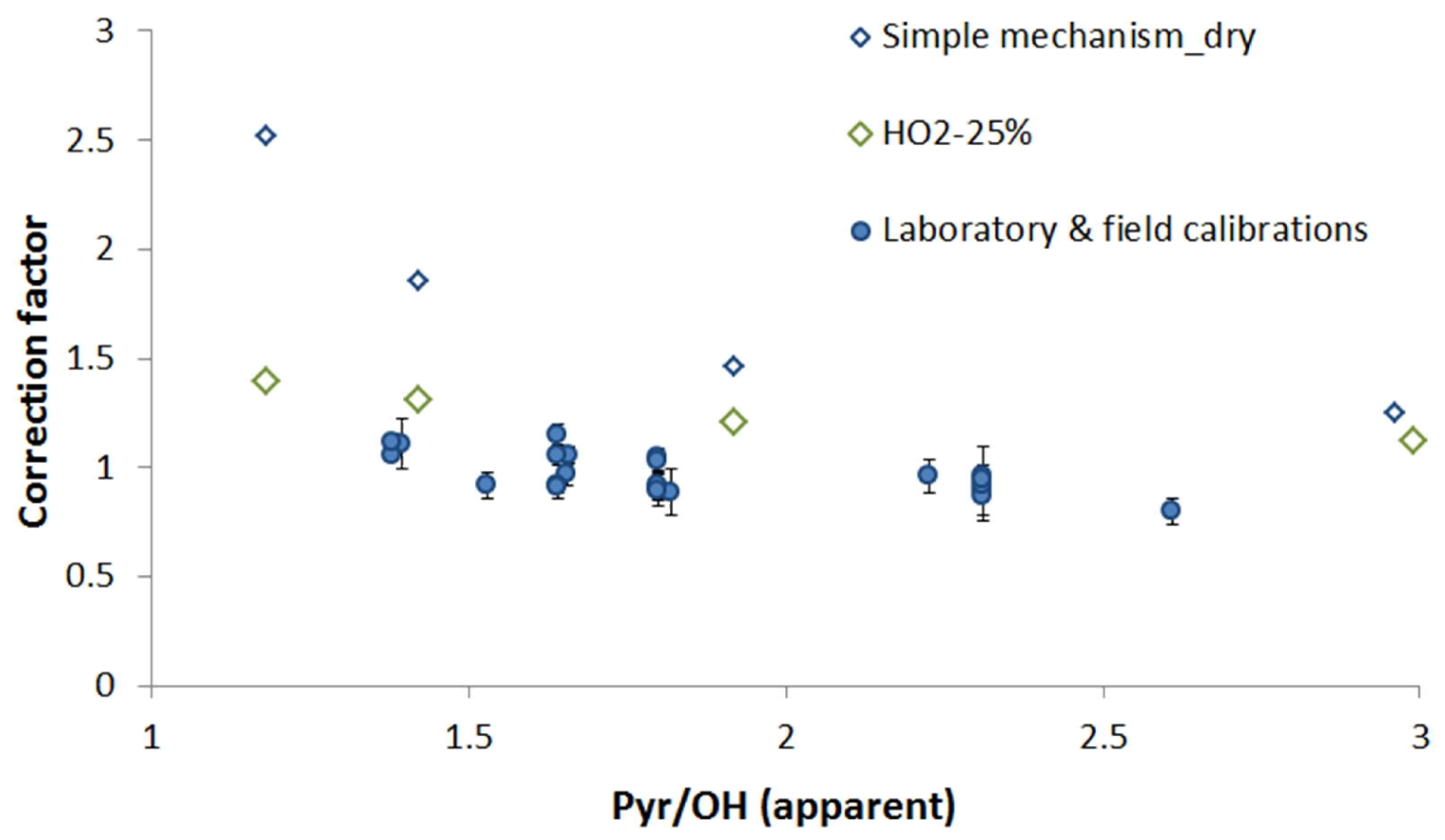

Figure S13: Comparison of simulated and measured correction factors required to correct for not operating the instrument under pseudo first order conditions. Correction factors are shown as a function of the Pyrrole-to-OH ratio. Measured correction factors (blues circles) as well as error bars are the same than in Fig. 7. The simulated correction factors stem from simulations conducted using the simple mechanism assuming the same concentration for $\mathrm{OH}$ and $\mathrm{HO}_{2}$ (blue open diamonds) and a $25 \%$ lower proportion of $\mathrm{HO}_{2}$ compared to $\mathrm{OH}$ (green open diamonds).

\section{Supplementary material 14: Assessment of $\mathrm{OH}$ reactivity uncertainties}

To assess the total uncertainty of ambient $\mathrm{OH}$ reactivity measurements it is necessary to take into account errors associated to each quantity involved in the $\mathrm{OH}$ reactivity calculations (Eq. 1), including the different corrections. When we account for the different corrections, the final $\mathrm{OH}$ reactivity is calculated by the following equation:

$$
k_{O H}=\frac{((C 3+\Delta C 3)-(C 2+\Delta C 2)}{(C 1-(C 3+\Delta C 3))} \cdot k_{p} \cdot C 1 \cdot F \cdot D
$$

Where $k_{O H}$ is the final total $\mathrm{OH}$ reactivity, $\mathrm{C} 3, \mathrm{C} 2$ and $\mathrm{C} 1$ the concentrations of pyrrole at different measurement steps (see the main manuscript), $\Delta \mathrm{C} 3$ the change in $\mathrm{C} 3$ due to the NO artifact, $\Delta \mathrm{C} 2$ the change in $\mathrm{C} 2$ due to a difference in $\mathrm{RH}$ between $\mathrm{C} 2$ and $\mathrm{C} 3, k_{p}$ the reaction rate constant of pyrrole with $\mathrm{OH}, \mathrm{F}$ the correction factor to apply for not operating the instrument under pseudo first-order conditions, and D the correction factor for dilution of ambient air inside the reactor.

Considering that uncertainties are only due to PTR-MS measurements of pyrrole concentrations, the above equation can be rearrange to express it in terms of measured signals (only for uncertainty determinations and not for reactivity quantification): 


$$
k_{O H}=\frac{((S 3+\Delta S 3)-(S 2+\Delta S 2)}{(S 1-(S 3+\Delta S 3))} \cdot k_{p} \cdot \frac{S 1}{\left(S_{m 19}+X_{r} \cdot S_{m 37}\right) \cdot R_{f}} \cdot F \cdot D
$$

Where, S3, S2, and S1 are the pyrrole signals recorded by the PTR-MS at $\mathrm{m} / \mathrm{z} 68$ during the different measurement steps, $\Delta \mathrm{S} 3$ and $\Delta \mathrm{S} 2$ the changes in pyrrole signals due to the NO artifact and changes in relative humidity, respectively, $\mathrm{R}_{\mathrm{F}}$ the PTRMS sensitivity to pyrrole, $\mathrm{S}_{\mathrm{m} 19}$ and $\mathrm{S}_{\mathrm{m} 37}$ the signals at $\mathrm{m} / \mathrm{z} 19\left(\mathrm{H}_{3} \mathrm{O}^{+}\right)$and $\mathrm{m} / \mathrm{z} 37\left(\mathrm{H}_{3} \mathrm{O}^{+}\left(\mathrm{H}_{2} \mathrm{O}\right)\right)$, respectively, and $\mathrm{X}_{\mathrm{r}}$ the normalization factor accounting for the humidity dependence of the PTR-MS sensitivity (determined experimentally as described by Hansen et al. (2015)).

Making the assumption that the normalization of pyrrole signals by $\mathrm{H}_{3} \mathrm{O}^{+}$and $\mathrm{H}_{3} \mathrm{O}^{+}\left(\mathrm{H}_{2} \mathrm{O}\right)$ does not bring additional errors, the terms producing uncertainties in the measurements are: $\mathrm{S} 1, \mathrm{~S} 2, \mathrm{~S} 3, \Delta \mathrm{S} 2, \Delta \mathrm{S} 3, \mathrm{k}_{\mathrm{p}}, \mathrm{R}_{\mathrm{f}}, \mathrm{F}$, and D.

Assuming that these variables are independent, we can calculate the total uncertainty for $\mathrm{OH}$ reactivity measurements using the following equation:

$$
U_{f(x 1, \ldots, x n)}^{2}=\int_{1}^{n}\left[\left(\frac{\partial f}{\partial x i}\right)^{2} \cdot u_{x i}^{2}\right]
$$

Applied to the total $\mathrm{OH}$ reactivity measurements, this gives the following equations:

$$
\begin{aligned}
& U_{R_{a i r}}^{2}=\left[\frac{(S 3+\Delta S 3) \cdot[(S 2+\Delta S 2)-(S 3+\Delta S 3)]}{\left(S 1-(S 3+\Delta S 3)^{2}\right.} \cdot \frac{1}{\left(S_{m 19}+X_{r} \cdot S_{m 37}\right) R_{f}} k_{p} \cdot F \cdot D\right]^{2} \cdot\left(\sigma_{S 1}^{2}\right) \\
& +\left[\frac{-1}{(S 1-(S 3+\Delta S 3)} \cdot \frac{S 1}{\left(S_{m 19}+X_{r} \cdot S_{m 37}\right) R_{f}} \cdot k_{p} \cdot F \cdot D\right]^{2} \cdot\left(\sigma_{S 2}^{2}+\sigma_{\Delta S 2}^{2}\right) \\
& +\left[\frac{(S 1-(S 2+\Delta S 2))}{\left(S 1-(S 3+\Delta S 3)^{2}\right.} \cdot \frac{S 1}{\left(S_{m 19}+X_{r} \cdot S_{m 37}\right) R_{f}} k_{p} \cdot F \cdot D\right]^{2} \cdot\left(\sigma_{S 3}^{2}+\sigma_{\Delta S 3}^{2}\right) \\
& +\left[\frac{(S 3+\Delta S 3)-(S 2+\Delta S 2)}{(S 1-(S 3+\Delta S 3)} \cdot \frac{S 1}{\left(S_{m 19}+X_{r} \cdot S_{m 37}\right) R_{f}} F \cdot D\right]^{2} \cdot\left(\sigma_{k p}^{2}\right) \\
& +\left[\frac{(S 3+\Delta S 3)-(S 2+\Delta S 2)}{(S 1-(S 3+\Delta S 3)} \cdot \frac{S 1}{\left(S_{m 19}+X_{r} \cdot S_{m 37}\right) R_{f}} k_{p} \cdot D\right]^{2} \cdot\left(\sigma_{F}^{2}\right) \\
& +\left[\frac{(S 3+\Delta S 3)-(S 2+\Delta S 2)}{(S 1-(S 3+\Delta S 3)} \cdot \frac{S 1}{\left(S_{m 19}+X_{r} \cdot S_{m 37}\right) R_{f}} k_{p} \cdot F\right]^{2} \cdot\left(\sigma_{D}^{2}\right) \\
& +\left[-\frac{(S 3+\Delta S 3)-(S 2+\Delta S 2)}{(S 1-(S 3+\Delta S 3)} \cdot \frac{S 1}{\left(S_{m 19}+X_{r} \cdot S_{m 37}\right) R_{f}^{2}} k_{p} \cdot F \cdot D\right]^{2} \cdot\left(\sigma_{R f}^{2}\right)
\end{aligned}
$$

Since the statistics for PTR-MS signals follow a poissonian distribution (De Gouw and Warneke, 2007): $\sigma_{S 1}=\sqrt{S 1}, \sigma_{S 2}=\sqrt{S 2}$, and $\sigma_{S 3}=\sqrt{S 3}$. These terms represent the random error (precision) of the PTR-MS measurements. To calculate the precision on $\mathrm{OH}$ reactivity 
measurements, it is therefore possible to consider only these three uncertainties as non-zero in the above equations.

Terms leading to systematic errors are: $\mathrm{k}_{\mathrm{p}}, \mathrm{R}_{\mathrm{f}}, \mathrm{F}$, and $\mathrm{D}$. Their relative uncertainties $(1 \sigma)$ are described below:

- $\quad \frac{\sigma_{k p}}{k_{p}}$ is estimated from the literature to be $8 \%$ (Dillon et al., 2012).

- $\frac{\sigma_{R_{f}}}{R_{f}}$ is calculated as the relative standard deviation of pyrrole calibrations performed during the campaigns and in the laboratory, and from the uncertainty on the pyrrole standard $(1 \sigma$ of $5 \%) . \frac{\sigma_{R_{f}}}{R_{f}}$ is estimated to be $12 \%$.

- $\frac{\sigma_{F}}{F}$ is calculated from the standard deviation of correction factors obtained for different standards and within a restrained range of pyrrole-to-OH ratios (1.4-2.2) assuming that the pyrrole-to- $\mathrm{OH}$ dependence of $\mathrm{F}$ on this range of ratios is small. The corresponding relative uncertainty is $9 \%$.

- $\frac{\sigma_{D}}{D}$ is calculated from uncertainties associated to different flow rates (PTR-MS sampling, reactor exhaust, addition of $\mathrm{N}_{2}$ and pyrrole) that are controlled by mass flow controllers (estimated at $1 \%$ ). The overall relative uncertainty to the dilution is estimated to be $2 \%$.

Finally, uncertainties for $\Delta \mathrm{S} 3$ and $\Delta \mathrm{S} 2$ are given below:

- $\Delta \mathrm{S} 2$ is calculated using the following equation: $\Delta S 2=p\left[\left(\frac{S m 37}{S m 19}\right)_{S 3}-\left(\frac{S m 37}{S m 19}\right)_{S 2}\right]$ (see equation (3) from the main manuscript), where $p$ is the slope of the linear relationship observed between the pyrrole signal and the m37/m19 ratio. Since the uncertainty on the $\mathrm{m} 37 / \mathrm{m} 19$ ratio is negligible $(\sim 0.05 \%)$, it is assumed that $\frac{\sigma_{\Delta S 2}}{\Delta S 2}$ depends only on the error associated to the slope and is estimated, from laboratory and field experiments, to be $12 \%$.

- $\Delta \mathrm{S} 3$ is calculated using a quadratic regression depending on NO: $\Delta S 3=a^{\prime} . N O^{2}+b^{\prime} . N O$. The relative uncertainty for $\Delta S 3$ is estimated by propagating errors on the determinations of $a^{\prime}$ and $b^{\prime}$ and on the NO measurements:

$$
\frac{\sigma \Delta S 3}{\Delta S 3}=\sqrt{\left(\frac{U_{\text {NOmeasurement }}}{N O}\right)^{2}+\left(U_{\text {parametrization }}^{\text {rel }}\right)^{2}}
$$

Errors associated to the determinations of $a^{\prime}$ and $b^{\prime}$ are estimated using the $1 \sigma$ confidence intervals of the quadratic regression (see Fig. S14.1). These errors are found to be dependent on the NO mixing ratio. 
The error on NO measurements is estimated using the specification given by the constructor for the $\mathrm{NO}_{\mathrm{x}}$ analyzer (Thermo Environmental Instruments, model 42C), i.e. a limit of detection of $0.4 \mathrm{ppb}$, and a relative precision of $4 \%$ determined experimentally.

$U_{\text {NOmeasurement }}=\frac{L O D}{3}+$ relative.precision $\times N O$

The overall relative uncertainty for this correction $\left(\frac{\sigma \Delta S 3}{\Delta S 3}\right)$ regarding the NO mixing ratio is shown in Fig. S14.2.

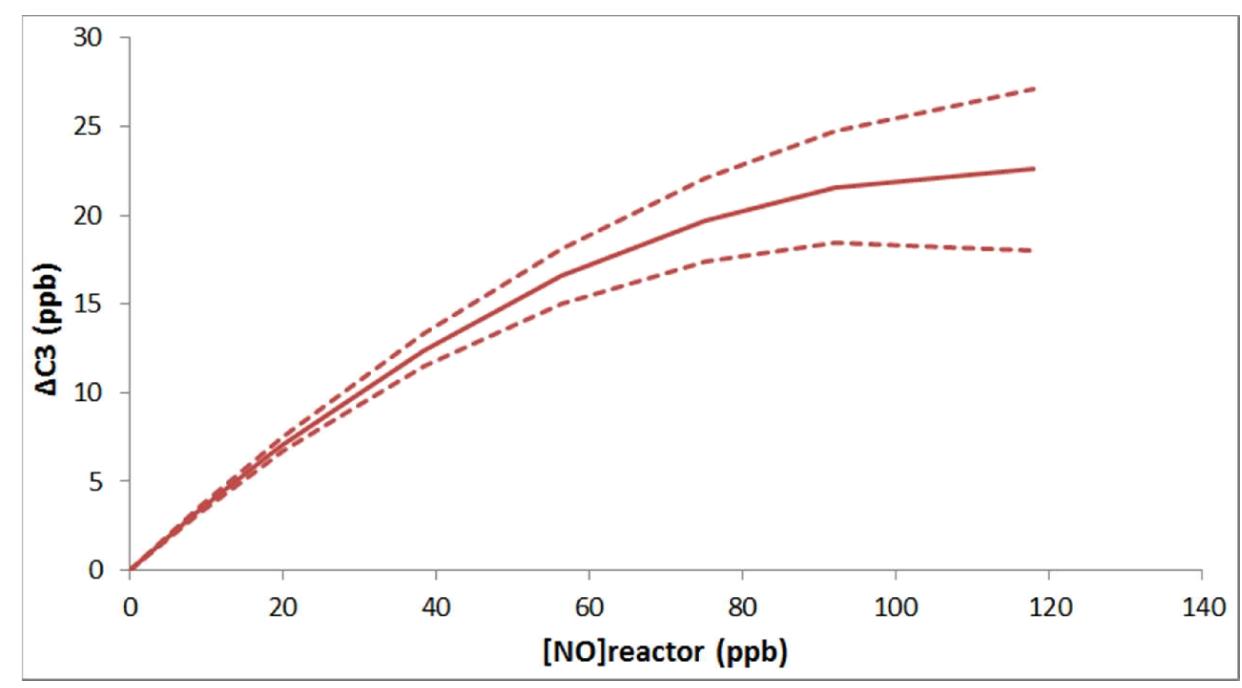

Figure S14.1: Change in $\mathrm{C} 3$ as a function of NO. The solid line corresponds to an estimated $\Delta \mathrm{C} 3$ using the quadratic regression determined experimentally for a pyrrole-to-OH ratio of 3.8 , for which the largest uncertainties are expected. The dashed lines display the $1 \sigma$ confidence interval calculated using errors associated to $a^{\prime}$ and $b^{\prime}$.

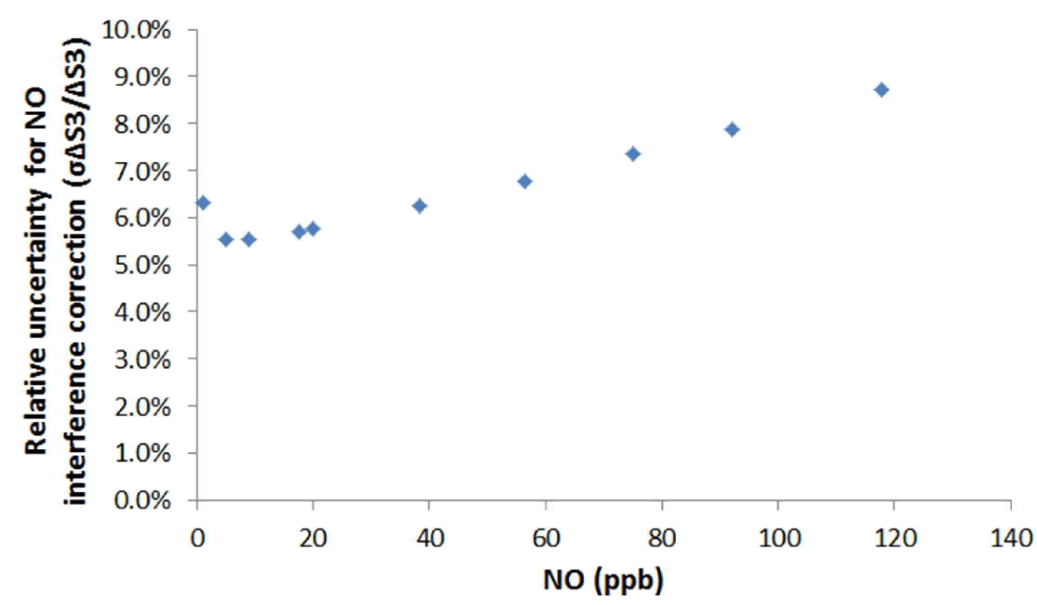


Figure S14.2: Trend of $\sigma \Delta S 3 / \Delta S 3$ with NO. The relative uncertainty for this correction is estimated by propagating errors associated to the determinations of $a^{\prime}$ and $b^{\prime}$ (quadratic regression of $\Delta \mathrm{C} 3=\mathrm{f}(\mathrm{NO})$ ) and the measurement error on $\mathrm{NO}$. 


\section{References}

Bossolasco, A., Faragó, E. P., Schoemaecker, C., and Fittschen, C.: Rate constant of the reaction between $\mathrm{CH}_{3} \mathrm{O}_{2}$ and $\mathrm{OH}$ radicals, Chem. Phys. Lett., 593, 7-13, 2014.

De Gouw, J. and Warneke, C.: Measurements of volatile organic compounds in the Earth's atmosphere using proton-transfer reaction mass spectrometry, Mass Spectrom. Rev., 26, 223257, 2007.

Dillon, T., Tucceri, M., Dulitz, K., Horowitz, A., Vereecken, L., and Crowley, J.: Reaction of Hydroxyl Radicals with C4H5N (Pyrrole): Temperature and Pressure Dependent Rate Coefficients, J. Phys. Chem. A., 116, 6051-6058, doi:10.1021/jp211241x, 2012

Fittschen, C., Whalley, L. K., Heard, D. E.: The Reaction of $\mathrm{CH} 3 \mathrm{O} 2$ Radicals with $\mathrm{OH}$ Radicals: A Neglected Sink for $\mathrm{CH} 3 \mathrm{O} 2$ in the Remote Atmosphere, Environ. Sci. Technol., $48,14,7700-7701,2014$

Hansen, R. F., Blocquet, M., Schoemaecker, C., Léonardis, T., Locoge, N., Fittschen, C., Hanoune, B., Stevens, P. S., Sinha, V., and Dusanter, S.: Intercomparison of the comparative reactivity method (CRM) and pump-probe technique for measuring total $\mathrm{OH}$ reactivity in an urban environment, Atmos. Meas. Tech. Discuss., 8, 6119-6178, doi:10.5194/amtd-8-61192015,2015 